\title{
Infectious bursal disease standardization and seroprevalence study in Ranchi in poultry
}

\author{
ANURADHA KUMARI AND ARUN PRASAD
}

\begin{abstract}
The work was planned to develop diagnostic assay using hyper immune sera and poultry sera with seroprevalence monitoring in Ranchi (Jharkhand). The best result for dot-ELISA was standardized with $1.2 \mu \mathrm{l}$ of BursaB2K and Gumboro strain, skimmed milk 1.5 per cent+gelatin 0.5 per cent+BSA 1 per cent as blocking solution, sera dilution of 1:10 and 1:500 conjugate dilution. Statistical analyses were showing there is a non-significant difference in results of dot-ELISA and ELISA test to detect specific anti IBDV antibodies. In the present study, dot-ELISA based seroprevalence study of 92 suspected poultry samples in 18 different places of Ranchi in the year 2014-15, revealed IBD antibodies existed in 38.04 per cent with sensitivity and specificity of 67.57 per cent and 81.82 per cent, respectively. Serodiagnosis helps in monitoring immune status of poultry flock in the area for IBD. There was large variation in IBD positive antibodies in different places of Ranchi, ranging between 14.29 per cent to 100 per cent by dot-ELISA. Similar degree of results were observed with two strains of live attenuated IBD antigen i.e. Bursa B2K (invasive intermediate) and Gumboro (intermediate) strain. Statistical analysis revealed non-significant difference between dotELISA and ELISA. Dot-ELISA can be taken as promising tool in field.
\end{abstract}

KEY WORDS : Dot-ELISA, IBD, Seroprevalence, Poultry

How TO CITE THIS PAPER : Kumari, Anuradha and Prasad, Arun (2015). Infectious bursal disease standardization and seroprevalence study in Ranchi in poultry. Res. J. Animal Hus. \& Dairy Sci., 6(2) : 109-114.

\section{MEMBERS OF RESEARCH FORUM}

Address for correspondence :

Anuradha Kumari, Division of Microbiology, Ranchi Veterinary College, Birsa Agricultural University, Kanke, RANCHI (JHARKHAND) INDIA

Email : lordshiva.lordshiva1@gmail.com

Associated Authors' :

Arun Prasad, Division of Microbiology, Ranchi Veterinary College, Birsa Agricultural University, Kanke, RANCHI (JHARKHAND) INDIA

Email : dr.arunkanke@gmail.com 